\title{
The detection of wave slamming from vibration measure- ments on a polar supply and research vessel
}

\author{
Anriëtte Bekker ${ }^{1, *}$, Christof M. van Zij1 ${ }^{1}$, and Clinton F. W. Saunders ${ }^{1}$ \\ ${ }^{1}$ Sound and Vibration Research Group, Department of Mechanical and Mechatronic Engineering, Stel- \\ lenbosch University, South Africa.
}

\begin{abstract}
The SA Agulhas II is a polar supply and research vessel, which operates in the stormy Southern ocean and icy Antarctic waters. She is predisposed to problematic stern slamming. Twelve accelerometer channels from a full-scale vibration measurement system were used to capture measurements of wave incidence on the main deck close to the water line. An automated slamming detection and classification algorithm is proposed to extract slamming incidents from expansive full-scale data. This method is based on image processing of scalograms which are produced by continuous transforms, using the Morlet wavelet. Slams are classified based on the time of incidence. It is shown that high crest factor stern slamming occurs as often as twice per minute.
\end{abstract}

\section{Introduction}

The automatic detection of wave slamming from acceleration measurements on a polar supply and research vessel is investigated. Slamming is the exposure of a vessel structure to large forces due to wave impacts for a short duration of time [1]. Often, slamming is followed by a global vibratory response known as whipping [2]. Stern slamming in combination with whipping induce vertical bending moments which influence the fatigue life and ultimate longitudinal strength of hull girders [1-4]. The SA Agulhas II (SAAII), is a polar supply and research vessel (length, $134 \mathrm{~m}$, width $22 \mathrm{~m}$ ), which supports operations in Antarctica and the Southern Ocean. Bow slamming is expected in head seas for ships with ice-going hull shapes as a result of the increased bow flare angle required for effective ice-passage [1]. However, on the SAAII, stern slamming is problematic as it inhibits oceanographic research operations [5]. Omer and Bekker [5] showed that, owing to its impulsive nature, wave slamming could be identified by the broadband excitation patterns in acceleration spectrograms close to the wave impact site. Slamming incidents concur with broadband vibration excitation, which result in line features on spectrograms. The authors highlighted that the segregation of bow and stern slams remains an importiant topic for future investigation. Against this backdrop, an automatic slamming detection algorithm is proposed towards the detection and classification of impulsive wave slamming events. It is envisioned that this algorithm will function within a full-scale monitoring system [6] which sets the requirement of computational efficiency towards real-time analysis.

\footnotetext{
*e-mail: annieb@sun.ac.za
} 


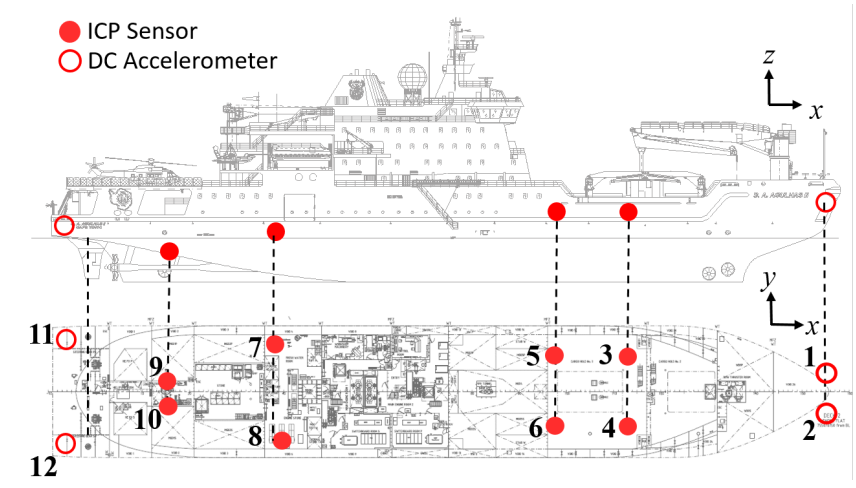

Figure 1: Layout of acceleration sensors used for slamming identification

\section{Methods}

\subsection{Vessel and full-scale measurements}

Full-scale measurements were performed on a voyage to the marginal ice zone South of Cape Town in July 2017. During 4 to 9 July wave slamming was encountered in open water as well as brash ice, comprising floes smaller than $3 \mathrm{~m}$, and an average thickness of 40 to $60 \mathrm{~cm}$. Large waves and slamming interrupted scientific work in icy and open water until the weather improved on 9 July. Twelve vertical acceleration measurement channels, close to the waterline, were selected for analysis (see Fig.1). Measurements were performed continuously at a sample rate of $2048 \mathrm{~Hz}$. The accelerometers included ICP type $\left(10 \mathrm{mV} / \mathrm{m} . \mathrm{s}^{-2}\right.$, $\pm 490 \mathrm{~m} . \mathrm{s}^{-2}$ pk., Model: PCB333B32) and DC type $\left(20 \mathrm{mV} / \mathrm{m} . \mathrm{s}^{-2}, 98.1 \mathrm{~m} . \mathrm{s}^{-2}\right.$ pk., Model: PCB3711B111OG) accelerometers.

\subsection{Slamming detection algorithm}

The proposed slamming detection algorithm is tasked to determine the relative timing and location of wave slamming on the SAAII. The incidence of wave slamming is non-periodic and random in amplitude. The hypothesis is that the broadband excitation property of impulsive wave slamming will transpire as line features on scalogram images obtained using wavelet transforms. It is proposed to use line detection algorithms to determine the approximate timing of slamming. A stepwise representation of the algorithm is presented in Fig.2.

- Step 1: Measurement selection and signal conditioning:In order to compare measurements from DC andd ICP sensors, signals were first detrended and then filtered to remove rigid body motion (high-pass filtering with a Butterworth filter, stopband of $0.5 \mathrm{~Hz}$ ) and higer engine harmonics (Butterworth filter with a pass band below $20 \mathrm{~Hz}$ ). The detrended signals were padded with ten seconds of zero data prior to filtering in order to eliminate filter settling artefacts in the time domain.

- Step 2: Create a scalogram image using a continuous wavelet transform (Morlet): The Morlet wavelet is ideal for the detection of impulsive events [7] and is described by the mathematical function:

$$
\psi(t)=\frac{1}{2 \pi} e^{\left(-\frac{t^{2}}{2} \beta^{2}\right)}[\cos \omega t+j \sin \omega t]=\frac{1}{2 \pi} e^{\left(-\frac{t^{2}}{2} \beta^{2}\right)} e^{j \omega t}
$$




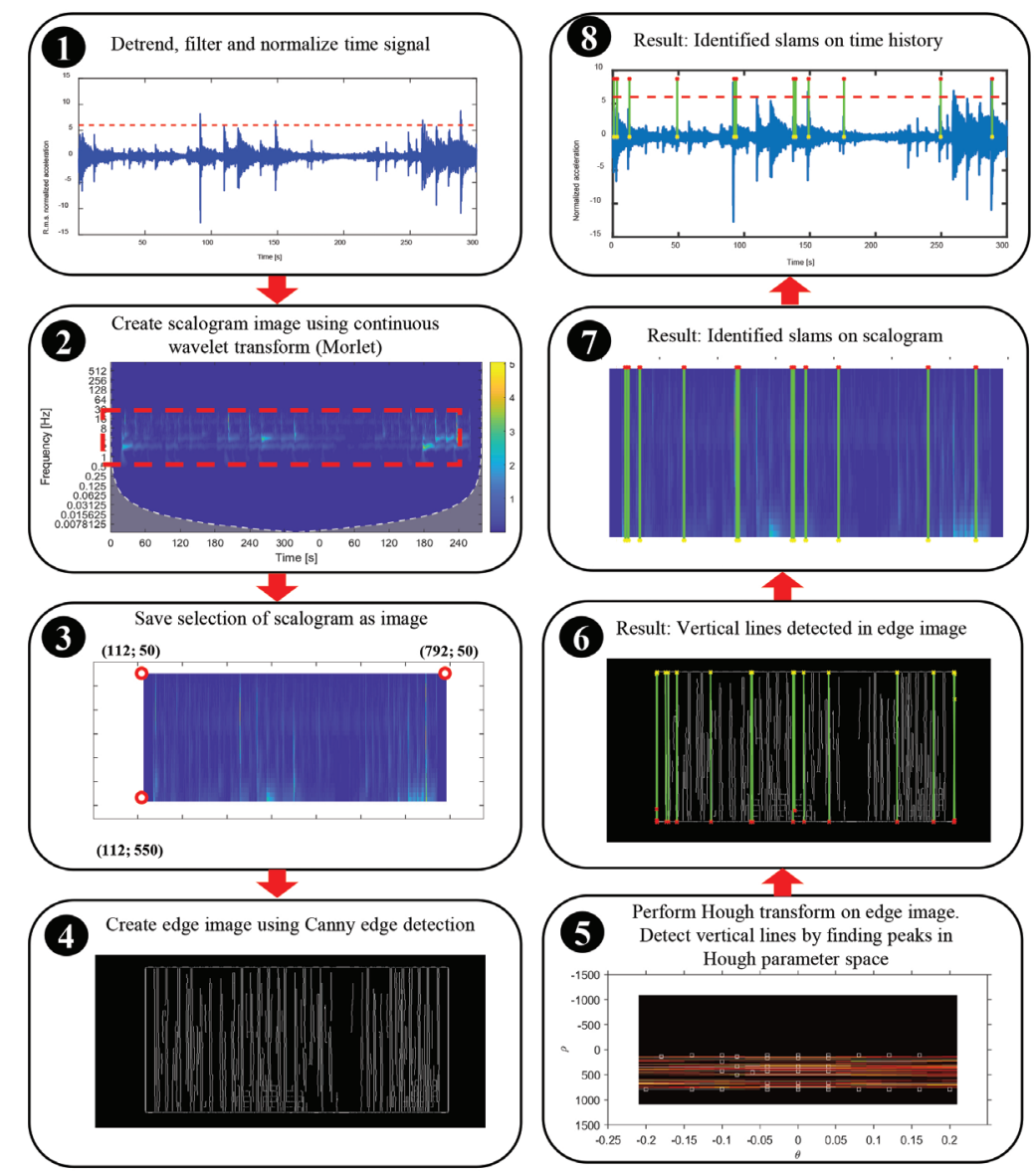

Figure 2: A diagram depicting the automatic slamming detection procedure.

The parameter, $\beta$, determines the geometric shape of the Morlet wavelet. It is expected that a larger $\beta$ is suitable to detect similarities with impulses in mechanical signals [7].

- Step 3 E 4: Image selection and Canny edge detection. The feature-rich frequency range in slamming scalograms is identified between $2 \mathrm{~Hz}$ and $24 \mathrm{~Hz}$. At $2 \mathrm{~Hz}$, the harmonic content of the propeller fundamental frequency disturbs the line-like slamming features. Likewise, the fundamental bending modes around $1.9 \mathrm{~Hz}$ and $3.4 \mathrm{~Hz}$ [8]. For this reason a subspace of the scalogram images was selected between $4 \mathrm{~Hz}$ and $24 \mathrm{~Hz}$. The scalogram colours were scaled to a grayscale image on which Canny edge detection was performed.

- Step 5: Perform a Standard Hough Transform and line detection: The Hough transform [9] is a non-linear mapping of points to sinusoidal lines. Concurrent points (peaks) in the Hough parameter space correspond to colinear points in the original image. Furthermore, the angle of the detected lines should concur with the cone of influence on the Morlet scalogram.

- Step 6 E 7: Map results from Hough parameter space to measurement time. The peaks detected in the Hough transform are mapped to the pixel coordinates in the edge image $($ Step 6$)$. The time resolution per pixel was $(792-112)=680$ pixels on the $\mathrm{x}$-axis of the 


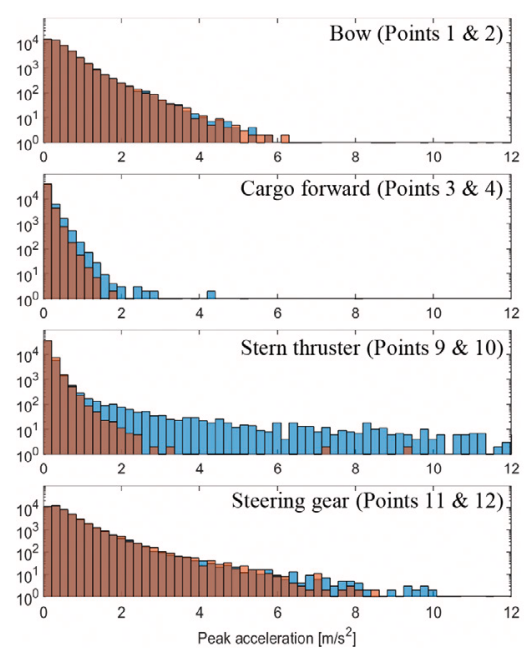

(a)
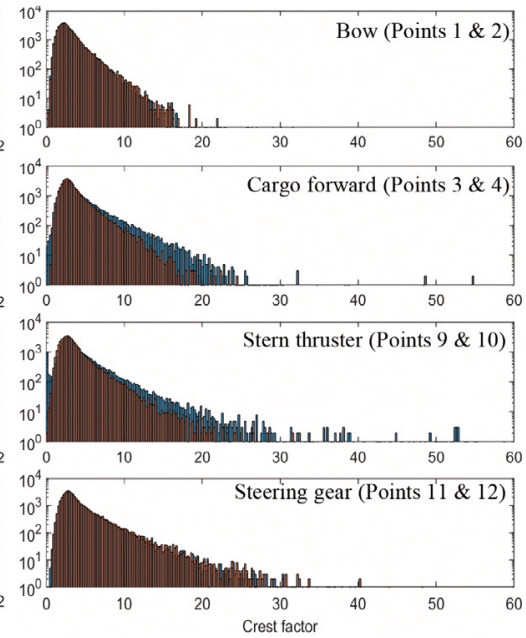

(b)

Figure 3: Histograms of the (a) peak acceleration and (b) crest factors of wave slamming.

plot area corresponds to the time scale (320 seconds) of the analyzed time signal ( $300 \mathrm{~s}$ measurements signal and $20 \mathrm{~s}$ zero-padding). The results were further interrogated against the scalograms as shown in Step 7.

- Step 8: Peak search in measurement time history. Line detection is used to determine the approximate timing of slamming incidents. Problematic stern slamming is isolated by assuming that measurements closer to the impact location, peak first and are more impulsive [5]. It was found that the algorithm was mostly accurate for slams with a crest factor (peak to r.m.s.) exceeding 6. This satisfies BS 6841-1 [10], which states a crest factor of 6 as the threshold for non-stationary signals.

\section{Results}

\subsection{Peak detection}

Fig. 3 presents histograms of the peak acceleration values and crest factors of identified slams on the stern and bow measurements. All the distributions are right-skewed and non-normal. The peak acceleration distributions(Fig. 3(a)) show that slamming causes the greatest peak values in the stern of the ship. Problems were intermittently experienced with sensors in the stern thruster section of the vessel as a result of overloads. The severity of the experienced slamming conditions is emphasized by the fact that the measurement ranges were set based on six years of prior measurement experience [6]. The peak values of the slams appear to be exponentially distributed, which suits the characteristics of a purely random and independent series of events. Fig. 3(b) shows that the forward cargo sensors experience significant crest factors as a result of slamming. The highest crest-factors are found in the stern section of the ship.

\subsection{Slamming classification}

It was decided to classify slams according to the channel which peaks first. Stern slams were identified from measurements in the steering gear room and stern thruster sections (Points 9, 

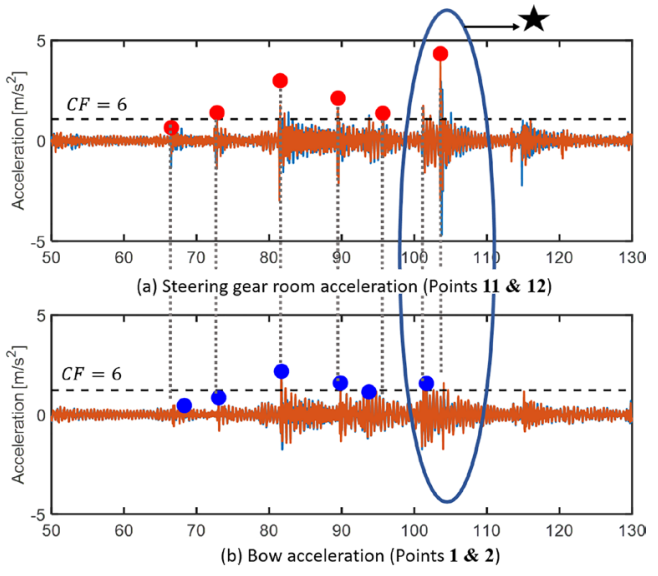

Figure 4: The influence of using different acceleration metrics to detect wave impact site.

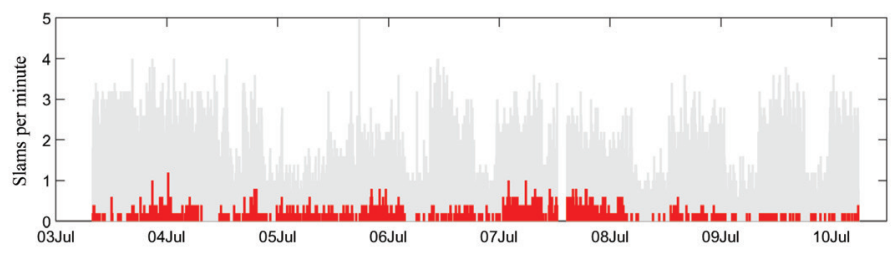

(a) Number of bow slams per minute.

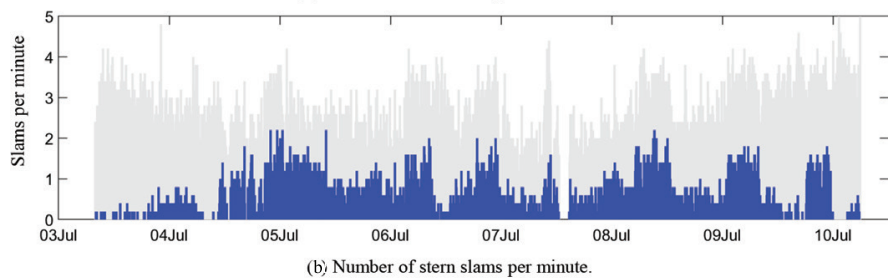

Figure 5: Slam counts per minute of a) bow-, b) stern slamming. All detected slams are indicated in grey. Slams with a $C F>6$ are displayed in color.

10,11 and 12), bow slamming from the bow chain lockers and forward cargo hold (Points 1,2,3 and 4) and hull slamming from measurements in the mid-ship. Fig. 4(a) and (b) present an example where the three greatest slams between $70 \mathrm{~s}$ and $90 \mathrm{~s}$ are interpreted as stern slams as the time signals peak prior to those in the bow. It is seen that the highest peak value and highest crest factor do not necessarily appear on the channel with the earliest peak time. A challenge is that closely-spaced slams lead to the mis-interpretation of the relative peak timing which no longer refers to the same slam. An overview of the detected bow- and stern slams is presented in Fig.5. The slam counts have been normalised to indicate the number of slams per minute. All detected slams are indicated in light grey for bow- and stern slamming. The darker plots on the foreground depict slams with a crest factor exceeding 6. It is clear that the stern of the ship is most frequently pre-disposed to larger slams. High crest factor slams are encountered up to twice per minute compared to slamming at the bow where the most frequent high crest factor slam rates hardly exceed once per minute. 


\begin{tabular}{|c|c|c|c|c|c|c|c|c|}
\hline \multirow{3}{*}{$\begin{array}{l}\text { Slamming } \\
\text { classification }\end{array}$} & \multicolumn{4}{|c|}{ All slams } & \multicolumn{4}{|c|}{ Slam $C F>6$} \\
\hline & \multicolumn{2}{|c|}{ Peak acceleration } & \multicolumn{2}{|c|}{ Crest factor } & \multicolumn{2}{|c|}{ Peak acceleration } & \multicolumn{2}{|c|}{ Crest factor } \\
\hline & $\begin{array}{c}\text { Median } \\
{\left[\mathrm{m} / \mathrm{s}^{2}\right]}\end{array}$ & $\begin{array}{c}\mathrm{IQR} \\
{\left[\mathrm{m} / \mathrm{s}^{2}\right]}\end{array}$ & Median & IQR & $\begin{array}{c}\text { Median } \\
{\left[\mathrm{m} / \mathrm{s}^{2}\right]}\end{array}$ & $\begin{array}{c}\mathrm{IQR} \\
{\left[\mathrm{m} / \mathrm{s}^{2}\right]}\end{array}$ & Median & IQR \\
\hline Bow slams & 0.116 & 0.196 & 2.73 & 1.5 & 0.388 & 0.579 & 7.50 & 3.00 \\
\hline Hull slams & 0.148 & 0.223 & 2.59 & 1.37 & 0.632 & 0.890 & 7.47 & 2.22 \\
\hline Stern slams & 0.234 & 0.568 & 3.37 & 2.72 & 1.180 & 1.205 & 8.62 & 4.471 \\
\hline
\end{tabular}

Table 1: Median and interquartile ranges (IQR) for non-normally distributed slamming.

\section{Conclusions and recommendations}

Random-amplitude, non-periodic wave slamming can be automatically extracted from long time histories using line detection on edge images of wavelet scalograms using the Morlet wavelet. Both, stern slamming and bow slamming produce high levels of peak acceleration. Larger magnitude stern slamming (Crest Factor $>6$ ) occurs more frequently than wave slamming in the rest of the hull and occurs as often as twice per minute. The present slamming detection algorithm is computationally expensive owing to the use of the continuous wavelet transform. Future work should focus on the quality of input images and the improved identification through de-noising techniques.

Funding from the National Research Foundation (NRF) is thankfully recognized.

\section{References}

[1] G.K. Kapsenberg, Philosophical Transactions of the Royal Society A: Mathematical, Physical and Engineering Sciences 369, 2892 (2011)

[2] D. Dessi, International Journal of Naval Architecture and Ocean Engineering 6, 1082 (2014)

[3] G. Storhaug, Which sea states are dimensioning for container vessels when whipping is included?, in International Conference on Ocean, Offshore and Arctic Engineering (San Francisco, USA, 2014)

[4] V. Bertram, Practical ship hydrodynamics (Elsevier Science, 2011), ISBN 9780080971506

[5] H. Omer, A. Bekker, Research and Development Journal of South Africa 32, 50 (2016)

[6] A. Bekker, M. Suominen, P. Kujala, R.J.O. De Waal, K.I. Soal, Ship Technology Research 65, 1 (2018)

[7] W.X. Yang, X.M. Ren, Eurasip Journal on Applied Signal Processing 2004, 1156 (2004)

[8] K. Soal, J. Bienert, A. Bekker, Operational modal analysis on the polar supply and research vessel the S.A. Agulhas II, in 6th International Operational Modal Analysis Conference, IOMAC 2015 (2015), ISBN 9788461738809

[9] R.O. Duda, P.E. Hart, Communications of the ACM 15, 11 (1972)

[10] BS 6841, BS 6841 Guide to measurement and evaluation of human exposure to wholebody mechanical vibration and repeated shock (1897) 